\title{
DE ECONOMISCHE EN SOCIALE TOESTAND VAN DE OPSTANDELINGEN UIT HET BRUGSE VRIJE, WIER GOEDEREN NA DE SLAG BIJ CASSEL (1328) VERBEURD VERKLAARD WERDEN
}

Kort na de slag bij Cassel werd in verschillende kasselrijen overgegaan tot de inbeslagname van de goederen van de opstandelingen. De verbeurdverklaringen ten nadele van de revolterenden in de kasselrijen Veurne, Cassel en Sint-Winoksbergen zijn sedert lang gepubliceerd ( $\left.{ }^{1}\right)$, terwijl de deelname van het Brugse Vrije totnogtoe hoofdzakelijk uit verhalende bronnen bekend was $\left({ }^{2}\right)$. Toch zijn ook voor de kasselrij van het Brugse Vrije een aantal verbeurdverklaringen bekend die pas nu gepubliceerd zijn ( $\left.{ }^{3}\right)$.

De door Pirenne uitgegeven confiscaties vormen een volume, dat door Vane Guy, ontvanger van de koning van Frankrijk, in 1331 werd opgesteld en door hem aan de Rekenkamer te Parijs werd overhandigd ( $\left.{ }^{4}\right)$. Voor het opstellen maakte de auteur gebruik van gegevens door (andere) agenten verzameld. Het heet immers : «Chest li livres des Inventores des hirritages des Flamencs ... si avant qu'il ont esté raporté par cheus qui les dis inventorez fisent $"\left({ }^{5}\right)$.

(1) H. Prrenne, Le soulevement de la Flandre maritime de 1323-1328, Brussel, 1900 (KCG.).

(2) Hieronder valt vooral het Chronicon comitum Flandrensium (Ed. J. J. De SMet, Corpus chronicorum Flandriae, t. I, Brussel 1837), blz. 184-209 te vermelden. Cf. H. Pirenne, op. cit., p. Xv n. 1 .

(3) J. Mertens, Les confiscations dans la chatellenie du Franc de Bruges apres la bataille de Casssel, Hand. K.C.G., CXXXIV, 1968, blz. 239-284.

(4) H. Pirenne, op. cit., blz. 1 : « Lequel livre Vaneguy a délivré à Parijs en la chambre des comptes ".

(5) ID., ibid., blz. 1. 
Ongetwijfeld is ook de door ons gepubliceerde rol, bij de aanvang van 1329 door Ottenin Machet ( ${ }^{1}$ ) opgesteld, een soortgelijke inventaris.

De meeste van de verbeurde goederen konden na de insbelagname niet rechtstreeks door de graaf uitgebaat worden en werden daarom in maart 1329 te Brugge "vercijnsd" voor een termijn van drie jaar. Gelijktijdig of zeer korte tijd later werd de tot ons gekomen inventaris van Ottenin Machet opgesteld.

De «vercijnsde» goederen moesten het verschuldigde bedrag betalen op twee termijnen 's jaars : op Sint-Jan ( 24 juni) en op Bamis (1 oktober). Bij het in cijns gevens is Ottenin Machet niet alleen opgetreden maar heeft zich door « boines gens", o. m. door Pieter Taisperc, Weitin Vindegoet, Jehan Volcrave, Henri VIpains en Jehan Utenbiezen, laten bijstaan ( ${ }^{2}$ ).

Het mag eigenaardig lijken dat deze confiscatielijst niet in het «boek» van Vane Guy is opgenomen. Het tijdstip van het tot stand komen van beide documenten verschaft er in alle geval geen verklaring voor, vermits Vane Guy's werk pas ongeveer twee jaar na Machet's aan de autoriteiten werd ter hand gesteld $\left({ }^{3}\right)$. Ongetwijfeld ligt de oplossing in de verschillende bevoegdheid van de twee auteurs : $O$. Machet is ontvanger van de graaf van Vlaanderen ( $\left.{ }^{4}\right)$; Vane Guy is « recheveres en Flandres de par Mons. le Roy" ( $\left.{ }^{5}\right)$. Hij geeft zijn document te Parijs af, waar H. Pirenne, of liever E. Mannier ( ${ }^{\circ}$ ) het in de Nationale Bibliotheek terugvond. De lijst bevat confiscaties verricht in de meest zuidelijke kasselrijen van het graafschap Vlaanderen : Bourbourg, Bergues, Cassel, Bailleul en Veurne ( $\left.{ }^{7}\right)$, terwijl nu blijkt, en ook vroeger reeds bekend

(1) Zie over hem : G. Browoon, Le régime juridique et économique du commerce de l'argent dans la Belgique du moyen age, passim en vooral t. I., blz. 215-217, Brussel, 1922 (Acad. roy. de Belgique, Cl. des Lettres, Mémoires in-80, t. XIV); zie ook : P. Rogcke, Het Florentijns geslacht Machet in Vlaanderen, in Appeltjes van het Meetjesland, XVI, 1965, blz. 188-196.

(2) J. Mertens, op. cit., passim.

(3) H. Pirenne, op. cit., blz. 1 en inleiding, blz. xL.

(4) ID., ibid., blz. xxxix.

(5) ID., ibid., blz. xxxviI n. 7 .

(6) ID., ibid., blz. XLI en Xul n. 1 .

(7) ID., op. cit. 
was $\left(^{1}\right)$, dat ook andere districten actief aan de opstand deelnamen. Bovendien werden ook buiten Bourbourg, Bergues, Cassel, Bailleul en Veurne confiscaties verricht, maar dan niet meer voor de rekening en door de ontvanger van de Franse koning, maar voor die van dé graaf van Vlaanderen en door zijn ontvanger ( ${ }^{2}$ ).

Keren wij terug tot de verbeurdverklaringen in het Brugse Vrije, waarvan de opbrengst - alles wijst erop : ontvanger van de graaf, niet opgenomen in het «boek» van Vane Guy, teruggevonden in het fonds van de Rekenkamer van Vlaanderen - volledig aan de graaf ten goede is gekomen. $\mathrm{Zij}$ werden verricht in de drie kwartieren van het Vrije, in enkele kleine steden en te Brugge zelf. Zoals reeds voor de andere deelnemende districten was vastgesteld ( ${ }^{3}$ ), blijken ook hier veeleer gegoede personen aan de opstand te hebben deelgenomen.

Als wij uitzondering maken voor hen die om één of andere reden, en meer bepaald omwille van hun rijkdom, afzonderlijk opgenomen worden in de bron - Gerard de Moor, Willem van Orscamp, Jan van Sijsele en Gillis van Rumbeke, waarvan alle bezittingen onder hun naam zijn opgetekend (4) - was het klassificatieelement voor de tekst geografisch; grosso modo werd volgende indeling gevolgd: 1) platteland (bladen 1 tot 14)

2) steden (bladen 16 tot einde).

(1) Blockomans, De bestraffing van den opstand van Brugge en Westelijk-Vlaanderen in 1328, Beknopte Hand. XVe Vl. Filologencongres 1940, blz. 38-45. - H. STEIN, Les conséquences de la bataille de Cassel pour la ville de Bruges et la mort de Guillaume De Deken, son ancien bourgmestre (1328), Bull. CRH., LXVIII, 1899, blz. 647-664. - N. De PAUw, L'enqulte de Bruges apris la bataille de Cassel, ibid., blz. 665-704. - H. Prrenne, op. cit., blz. 189.

(2) Zie blz. 1131, n. 3. - H. NkL1s, Inventaire des Comples en roulcaux, Brussel, 1914, nr. 2016. H. PIrenne, op. cit., blz. xxxvi1-xxxix.

(3) H. Pirenne, op. cit., blz. Xxxiv ; G. Des Marez, op. cit., blz. 176-183 ; L. HenDRICkx, De sociale samenstelling van het Vlaamsche leger in den slag bij Cassel (1328), Nederlandsche Historiebladen, II, 1939, blz. 90.

(4) Jan van Sijsele is een edelman. Toch is de genealogie voor deze periode voor de heren van Sijsele niet gepubliceerd. (CF. Chanoine de Joigny, Manuscrit relatif aux seigneuries de Flandre, uitg. H. de Lnaburo-Strrum, Handelingen Oudheid- en Geschiedkundigen Kring oan Audenaerde, VII, 1926, en VIII, 1931 ; J. GaIllLARD, Bruges et le Frane, 1857-1864, 6 dln). Willem van Oostkamp en Gillis van Rumbeke behoren tot de meest vooraanstaande poorters te Brugge (Zie N. De PAUw, op. cit., blz. 673 en 687). 
Op folio 15 en op een deel van folio 16 zijn de goederen van de reeds genoemde vier personen opgetekend. De eerste veertien bladen zijn verder ingedeeld per vierschaar (Noord-, Oost- en West-Vrije) (1); voor elke vierschaar is een indeling per parochie gevolgd.

In het Oost-Vrije werden confiscaties verricht ten nadele van 48 personen, in het Noord-Vrije ten nadele van 23 personen en in het West-Vrije ten nadele van 71 personen.

In de steden zijn practisch alleen confiscaties van huizen te vermelden : te Brugge werden ten nadele van 24 personen 33 huizen (of delen ervan) verbeurd verklaard, samen met twee wisselkantoren $\left({ }^{2}\right)$; te Oostende werden 11 huizen verbeurd ten nadele van 9 personen, te Diksmuide 12 huizen, te Damme vijf, te Oudenburg vier en te Gistel één huis, ten nadele van telkens een zelfde aantal personen.

Wanneer wij voor de inwoners der plattelandsgemeenten, de samenstelling van hun eigendom nagaan, dan kunnen wij de inlichtingen samenvatten als weergegeven in tabel $I$.

Voor het Oost-Vrije waren er 48 personen die verbeurdverklaringen ondergingen; in het Noord-Vrije waren er 23 en in het West-Vrije 71. In totaal komen dus 142 plattelandsbewoners in onze lijst voor, tegenover 55 stedelingen. De verhouding is ongeveer 2,6: 1 . In het algemeen zijn de bezitters van " manoirs " talrijker dan de eigenaars van huizen, dit opnieuw in tegenstelling met de stadsbewoners. Alleen in de Oost-vierschaar overtreft het aantal personen - 27 - die een huis of een deel ervan bezitten dit van de bezitters van een « manoir» $\left({ }^{3}\right)$. Voor de drie vierscharen samen zijn de cijfers : 45 bezitters van huizen, 70 bezitters van een manoir (verhouding $1: 1,8$ ).

(1) Voor de omschrijvingen en de erin vermelde parochies, zie tabel I en de op blz. $1131, \mathrm{n} .3$ vermelde publikatie.

(2) O.m. Glais en Willem De Deken. De twee wisselaars waren Loy van Cassel en Willem van Ansame, beide vermeld in het begin van de xrve eeuw. (CF. R. DE Roover, Money, Banking and Credit in mediaeval Bruges, Cambridge, Massachusetts, 1948, blz. 192 nn. 38 en 39). De door L. Gilliodts vermelde « registre des ôtages 1328 » (Inventaire, Introduction, blz. 16 n. 8) werd niet teruggevonden.

(3) Tabel $I$. 


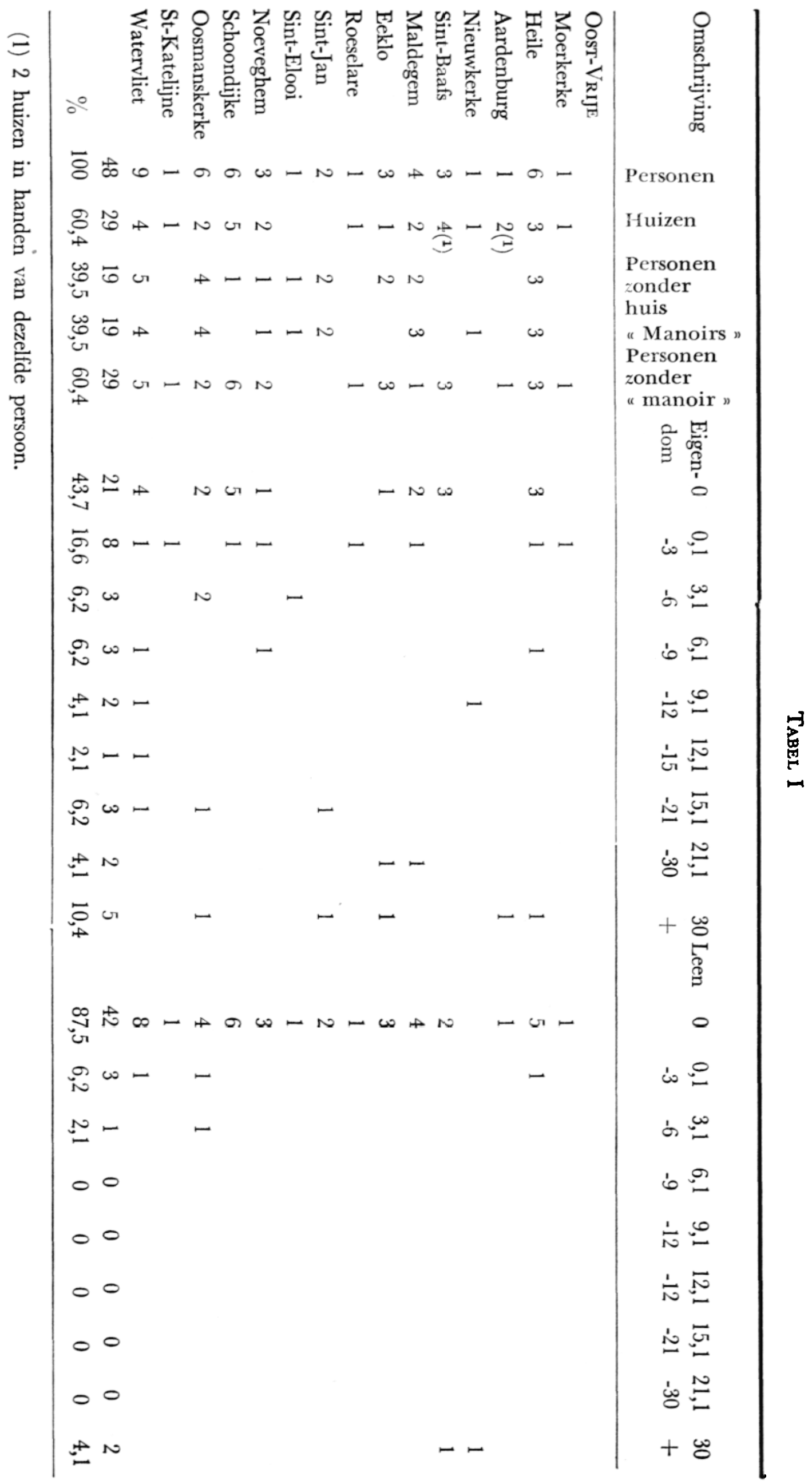




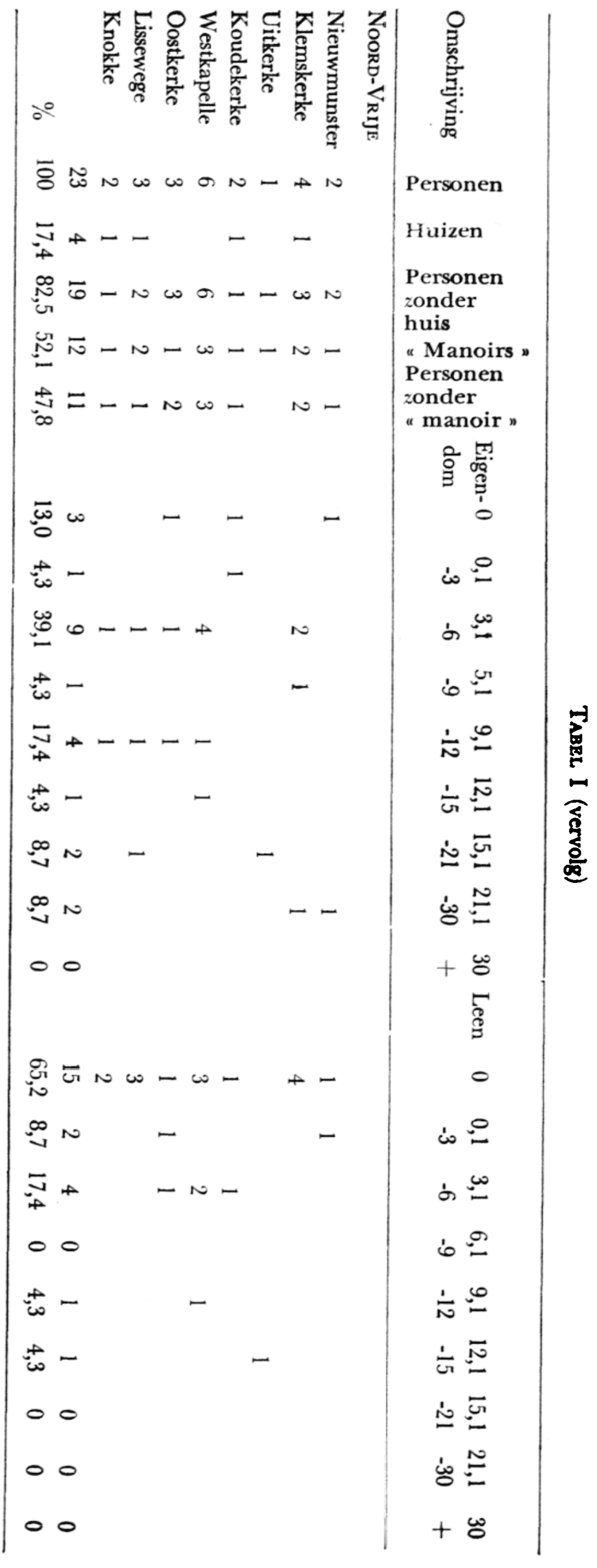




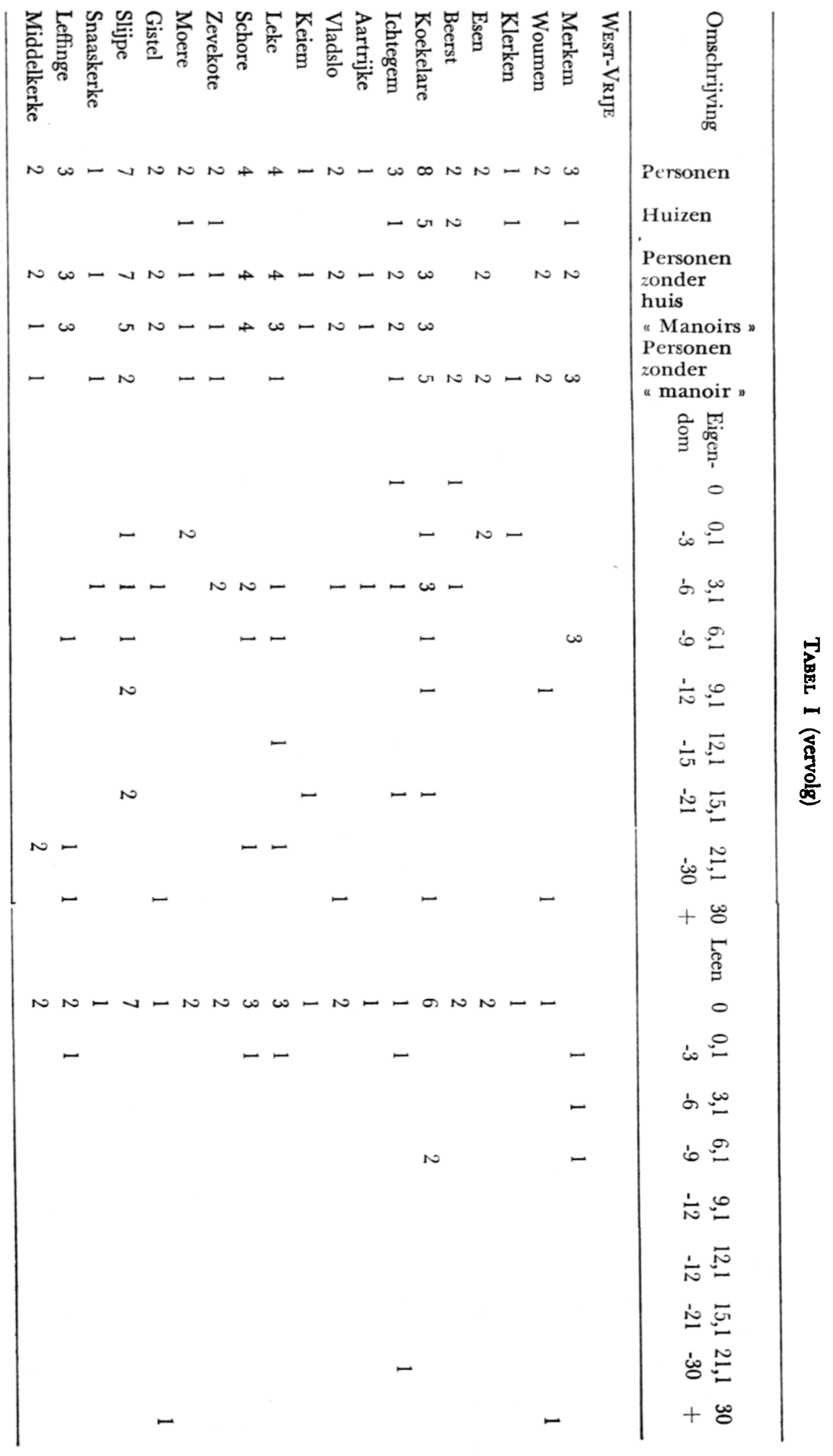


TABEL I (vervolg)

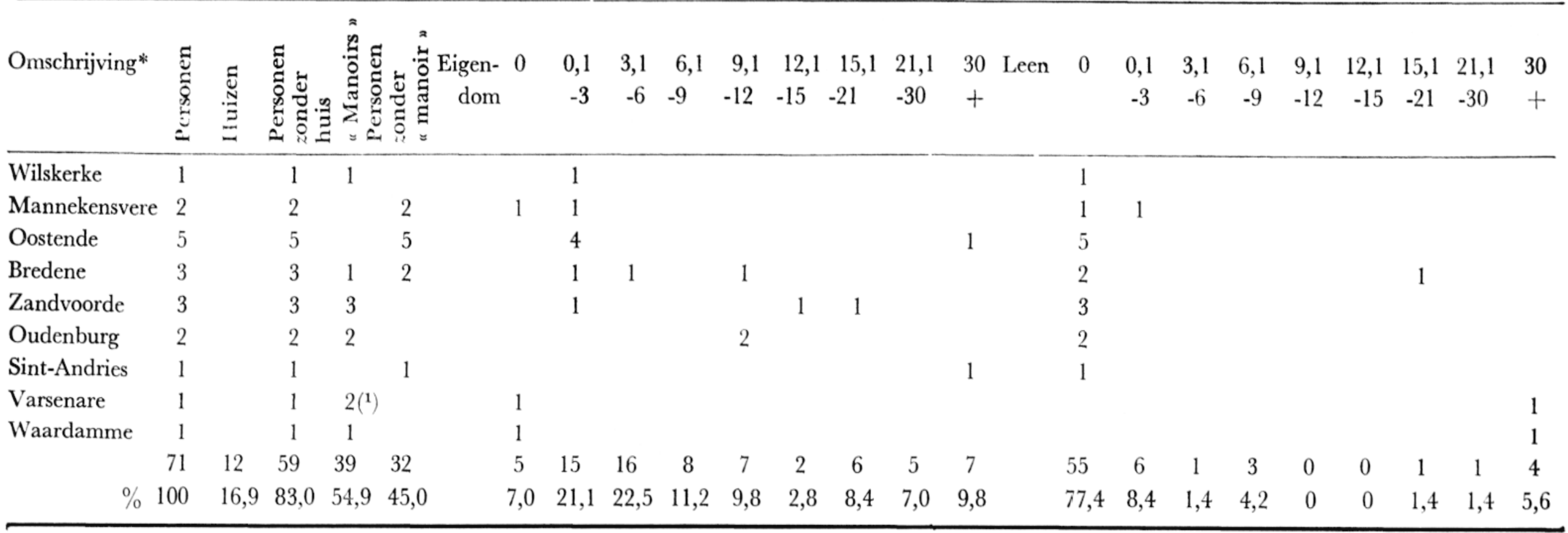

(*) Volgende gemeenten liggen in Nederland, provincie Zeeland (Zeeuws-Vlaanderen) : Aardenburg, Nieuwkerke, Schoondijke. Ook de nog bestaande en verdwenen parochies Heile, Sint-Baafs, Sint-Elooi, Oosmanskerke en Sint-Katelijne liggen in hetzelfde gebied. Noeveghem konden wij niet identificeren. Roeselare is een verdwenen stadje bij de Belgisch-Nederlandse grens tussen Aardenburg en Sint-Margriete (prov. Oost-Vlaanderen, arr. Eeklo, kant Kaprijke).

Verder liggen in België, prov. Oost-Vlaanderen, arr. Eeklo, kant. Eeklo : Maldegem en Eeklo ; in de prov. Oost-Vlaanderen, arr. Eeklo, kant. Kaprijke : Sint-Jan-in-Eremo en Watervliet.

In de prov. West-Vlaanderen liggen : in arr. Brugge, kant. Brugge : Moerkerke, Nieuwmunster, Uitkerke, Koudekerke-Heist, Westkapelle, Oostkerke, Lissewege, Knokke, Sint-Andries, Varsenare en Waardamme; in arr. Oostende, kant. Brugge: Klemskerke; in arr. Diksmuide, kant. Diksmuide : Merkem, Woumen, Klerken, Esen, Beerst, Vladslo ; in arr. Diksmuide, kant. Torhout : Koekelare ; in arr. Oostende, kant. Torhout : Ichtegem ; in arr. Brugge, kant. Torhout: Aartrijke ; in arr. Diksmuide, kant. Nieuwpoort : Keiem ; in arr. Diksmuide, kant. Gistel : Leke ; in arr. Oostende, kant. Nieuwpoort : Schore, Middelkerke, Mannekensvere ; in arr. Oostende, kant. Gistel : Zevekote, Moere, Gistel, Slijpe, Snaaskerke, Leffinge, Wilskerke, Zandvoorde en Oudenburg; in arr. Oostende, kant. Oostende: Oostende en Bredene.

(1) 2 manoirs in handen van dezelfde persoon. 
De eigenaars van gronden overtreffen duidelijk het aantal leenhouders: ongeveer $80 \%$ van het totaal bezitten eigendommen, slechts $20 \%$ zijn leenhouder $\left({ }^{1}\right)$. Slechts 20 personen d.w.z. $14,8 \%$ bezitten zowel eigendommen als foncierleen. M.a.w. slechts ongeveer $5 \%$ van de leenhouders zijn niet tevens eigenaar van één of ander perceel grond.

Als wij de klasse der ongeveer $10 \%$ eigenaars met een bezit van meer dan 30 gemeten, nog verder willen ontleden, dan blijkt dat 9 van de 12 personen een bezit hebben tussen 30 en 50 gemeten. Slechts 3 personen bezitten meer dan 50 gemeten. De voornaamste uitgestrektheden zijn in handen van Jacob Garencopere $\left({ }^{2}\right)$ te Sint-Andries (62 gem.) en van Rogier Moenac ( $\left.{ }^{3}\right)$ te Gistel (65 gem.). In het Noord-Vrije is Rikewart van Straten ( $\left.{ }^{4}\right)$, met niet eens 30 gemeten, de voornaamste grondbezitter. In dit kwartier zijn er evenmin belangrijke leenhouders; niemand houdt er meer dan 15 gemeten in leen. In het Oostkwartier houdt Huwes Blauwel 45 gemeten in leen te Nieuwkerke en Willem $\mathrm{f}$. Hughe houdt ongeveer 70 gemeten in leen te St.-Baafs-Aardenburg. In het Westkwartier houden twee personen meer dan 30 gemeten in leen : én houdt tussen 50 en 100 gemeten ( $\left.{ }^{5}\right)$ terwijl Rogier van Coudenbrouc ( $\left.{ }^{8}\right)$, die te Waardamme 200 gemeten in leen houdt van de graaf, de belangrijkste leenhouder is.

Geraard de Moor bezit ongeveer 100 gemeten in eigendom in het Oost-Vrije; te Brugge houdt hij Beaupré, een leen van 28 gemeten met molen van de graaf. Jan van Sijsele heeft te Sijsele «veel» grond, en heeft bezittingen te Keiem en te Landegem. Zijn eigendom is waarschijnlijk het belangrijkste van alle hier vermelde goederen. Hij bezit renten en molens, alsmede de heer-

(1) Tabel I.

(2) J. Garencopere is een Brugs poorter behorend tot de stadsmagistraat (L. GILLiodTs, Inventaire, I. Brugge, 1871, blz. 318).

(3) Zie over hem: H. Purenne, op. cit., blz. xxxill n. 3.

(4) Lid van de familie van Straten; zoon van Willem VIII (?). (Zie Ch. Pror, Notice historique et généalogique de la maison de Straten, Brussel, 1877, blz. 44).

(5) Met name Clais De Deken te Brugge-Varsenare-Sint-Andries.

(6) R. Van Coudenbrouc is een Brugs poorter behorend tot de stadsmagistraat (zie o.m. L. Gilliodts, Inventaire, VI, bl. 529-530). 
lijkheid Sijsele. Gillis van Rumbeke heeft ruim honderd gemeten te Rumbeke, te Bredene en te Zandvoorde gelegen. Hij houdt van Wouter van Wervik acht bunder in leen te Rumbeke en bezit verder tiendlenen en renten. Voor Willem van Oostkamp wordt slechts weinig foncier vermeld, wel belangrijke geldlenen, tienden en molens. Het is hier meteen wel duidelijk waarom deze vier personen afzonderlijk werden vermeld...

Alles bij elkaar is het aantal verbeurdverklaringen zeer gering. Op het platteland tellen wij 146 individuěn met inbegrip van de vier afzonderlijk vermelde personen; in de steden 55 personen; in totaal zijn er 201 opstandelingen wier goed werd inbeslaggenomen. In vergelijking met de 3185 door $\mathbf{H}$. Pirenne vermelde burgers ( ${ }^{1}$ ) is dit zeer weinig, nauwelijks 6,3\%. Staan wij hier voor een zeer onvolledig staal van de verrichte confiscaties of was de graaf zoveel milder dan de Franse koning? Of nog: nam het Brugse Vrije in zoveel geringer mate aan de opstand deel ? Het moet hier een open vraag blijven.

Van de in het Soulevement de la Flandre maritime vermelde personen zijn er 891 die niets bezitten, 1222 die geen grond bezitten maar slechts een huis en 1072 die ook land bezitten ( $\left.{ }^{2}\right)$.

In de door ons gepubliceerde verbeurdverklaring komen geen personen voor die niets bezitten. De meeste stadsbewoners bezitten slechts een huis maar alle bewoners van het platteland bezitten grond.

De vraag blijft hoeveel personen aan de opstand hebben deelgenomen zonder eigenaar te zijn. Het is immers aanneembaar dat de overheid geen belang stelde in de optekening van opstanlingen waarvoor zij geen goederenbeheer verkreeg m.a.w. voor de bezitlozen.

In de veronderstelling dat de cijfers van de inventaris van Vane Guy juist zijn, kan geredelijk verondersteld worden dat de cijfers in het Vrije hiermee in rechtstreekse verhouding staan, maar het

(1) H. Pirenne, op. cit., blz. cix-Lxv.

(2) L. HeNDrickx, op. cit., ble. 88. Het is waarschijnlijk dat nog andere confiscaticlijsten hebben bestaan. (Zie 0.m. L. Gilliodrs, Inventaire, Introduction, blz. 16 en Archives départementales du Nord, série $B, n^{\circ} 6950$ ). 
feit dat hier geen bezitlozen vermeld zijn brengt de betrouwbaarheid van het getal 891, opgemaakt uit de inventaris van Vane Guy opnieuw in het gedrang ( $\left.{ }^{1}\right)$. Het is immers goed mogelijk dat de bezitlozen maar om éen of andere reden genoteerd werden; bij voorbeeld omdat ze gesneuveld waren. Anderen bleken misschien niet « markant» genoeg om te worden opgetekend. In elk geval had, economisch en financieel gezien, de agent van de koning, evenmin als die van de graaf, enig belang bij het optekenen van hun naam.

Zoals blijkt uit de confiscatielijst, werden uit Brugge 24 personen, wier goederen werden verbeurd verklaard, opgetekend; uit Diksmuide twaalf. Voor Veurne en Nieuwpoort zijn de cijfers 144 en $174\left({ }^{2}\right)$. Werden het Brugse Vrije en de erin gelegen steden dan toch slechts subsidiair door de opstand beroerd? In alle geval is het aandeel van het gebied dat het dichtst bij Veurne-ambacht lag - het West-Vrije - blijkens de confiscatierekening het aanzienlijkst, terwijl anderszijds weer blijkt dat het aandeel van Brugge groter is geweest dan uit de hier besproken confiscatielijst kan opgemaakt worden $\left({ }^{3}\right)$.

Kunnen wij dus, op grond van de bestaande teksten, moeilijk een uitspraak doen over de rijkdom van de opstandelingen in het algemeen, wij kunnen het des te beter voor wat betreft de rijkdom van hen, wier goed achteraf werd verbeurd verklaard : diegenen, die goederen bezaten behoorden zeker tot een klasse die Pirenne kwalificeerde als kleine grondbezitters en vrije boeren ( $\left.{ }^{4}\right)$.

In het Westkwartier is de eigendomssituatie van de bevolking het gunstigst. In het Oostkwartier zijn wel $10 \%$ van de personen bezitters van minimum 30 gemeten grond, 43,7\% bezitten evenwel geen landerijen. Het grondeigendom lijkt evenrediger verdeeld in het Noord-Vrije.

In 't algemeen is slechts een minderheid in het bezit van leengronden. Opnieuw lijkt de toestand in het Oost-Vrije het ongunstigst in sociaal opzicht. In het Noord-Vrije is het kleine leengoed duidelijk

(1) H. Prrenne, op. cit., blz. hix-Lxv.

(2) ID., ibid., blz. LIX en LXII.

(3) N. De Pauw, op. cit., blz. 665-704. Zie ook blz. 1140, n. 2.

(4) H. Pirenne, op. cit., blz. xxxv. 
meer verspreid, maar alles samen lijkt de toestand toch het best uitgebalanceerd in het Westkwartier. Het is bijgevolg in het WestVrije, dichter bij de haard van de opstand gelegen, dat sociaal beter gesitueerden aan de opstand deelnamen. In het Oost-Vrije lijkt de sociale laag van heel wat minder niveau. Dit geldt ook voor de Noordvierschaar waar het aantal verbeurdverklaringen het geringst is.

Er dient evenwel opgemerkt dat het staal als geheel zeer weinig uitgebreid is en dat in het bijzonder het West-Vrije $50 \%$ van het totaal der verbeurdverklaringen in de kwartieren van het Vrije omvat. Daarom hebben wij een gecorrigeerde tabel van bezittingen opgesteld waarin het aandeel van iedere vierschaar tot 100 werd herleid. Op deze wijze werd het relatief belang van iedere vierschaar hetzelfde. Aldus bekomen wij volgende standaardindeling der bezittingen :

\begin{tabular}{ccc}
\hline Totaal in gemeten & Eigendommen in $\%$ & Lenen in $\%$ \\
0 & 21,1 & 77,4 \\
$0,1-3$ & 14,0 & 7,1 \\
$3,1-6$ & 22,6 & 7,0 \\
$6,1-9$ & 7,2 & 1,4 \\
$9,1-12$ & 10,4 & 1,4 \\
$12,1-15$ & 3,1 & 1,4 \\
$15,1-21$ & 7,8 & 0,5 \\
$21,1-30$ & 6,6 & 0,5 \\
$30,1-\ldots$ & 6,7 & 3,2 \\
\hline
\end{tabular}

Het afzonderlijk patroon van het West-Vrije stemt het best met deze standaardindeling overeen ( $\left.{ }^{1}\right)$. Voor de eigendommen is de afwijking in de andere omschrijvingen nagenoeg dezelfde, en bijna dubbel zo groot als voor het West-Vrije. Ook voor de lenen is de afwijking van het standaardpatroon in het NoordVrije dubbel zo groot als in het West-Vrije. De afwijking van de derde omschrijving ligt tussen die van beide andere in.

Zo wij met het totaal der geëxploiteerde bezittingen (zonder onderscheid te maken tussen leen en eigendom) rekening houden, krijgen wij volgende tabellen:

(1) Voor de hierboven vermelde cijfers : zie tabel $\mathbf{I}$. 
TABEL II

TotaAl bezit in Exploitatie (Zonder onderscheid tussen eigendommen en leengronden)
Personen 0
$0,1-3 \quad 3,1-6$
$6,1-9 \quad 9,1-12 \quad 12,1-15$
$15,1-21$
$21,1-30$
30 en meer

NOORD-VRIJE

Nieuwmunster

1

Klemskerke

Uitkerke

Koudekerke

Westkapelle

Oostkerke

Lissewege

Knokke

23

$\% \quad 100$

$\begin{array}{ccccc} & 1 & & & \\ & & 2 & 1 & \\ & 1 & 1 & & \\ & & 2 & & 1 \\ & & 1 & 1 & 1 \\ & & 1 & & 1 \\ 0 & & 1 & & 6 \\ 0 & 8,7 & 8 & 2 & \\ & & 34,7 & 8,7 & 26,1\end{array}$

\begin{tabular}{|c|c|c|c|c|}
\hline & & & $\begin{array}{l}1 \\
1\end{array}$ & \\
\hline 3 & & & 1 & \\
\hline 1 & & & & \\
\hline 1 & & 1 & & \\
\hline 1 & & & & \\
\hline 6 & 0 & 1 & 3 & 1 \\
\hline 26,1 & 0 & 4,3 & 13,0 & 4,3 \\
\hline
\end{tabular}

Oost-VRije

Moerkerke

Heile

Aardenburg

Nieuwkerke

Sint-Baafs

Maldegem

Eeklo

Roeselare

Sint-Jan

Sint-Elooi

Noeveghem

Schoondijke

Oosmanskerke

100

$8,7 \quad 34,7$

8,7

$$
1
$$

1

1

1

1

1

1

1

1

1

1

1

1

Sint-Katelijne

Watervliet.

1

9

48
$\% \quad 100$

1

5

1

1

2

1

1

$\% \quad 100$

$\begin{array}{cc}3 & 2 \\ 19 & 9 \\ 39,6 & 18,7\end{array}$

$\begin{array}{llllllc} & 1 & 1 & 1 & 1 & & \\ 2 & 3 & 2 & 1 & 3 & 2 & 7 \\ 4,1 & 6,2 & 4,1 & 2,1 & 6,2 & 4,1 & 14,6\end{array}$


Tabel II (vervolg)

\begin{tabular}{|c|c|c|c|c|c|c|c|c|c|c|}
\hline Omschrijving & Personen & 0 & $0,1-3$ & $3,1-6$ & $6,1-9$ & $9,1-12$ & $12,1-15$ & $15,1-21$ & $21,1-30$ & $\begin{array}{l}30 \text { en } \\
\text { meer }\end{array}$ \\
\hline \multicolumn{11}{|l|}{ West-VRije } \\
\hline Merkem & 3 & & & & & 2 & & 1 & & \\
\hline Woumen & 2 & & & & & & & & & 2 \\
\hline Klerken & 1 & & 1 & & & & & & & \\
\hline Esen & 2 & & 2 & & & & & & & \\
\hline Beerst & 2 & 1 & & 1 & & & & & & \\
\hline Koekelare & 8 & & 1 & 3 & & 1 & 1 & 1 & & 1 \\
\hline Ichtegem & 3 & & & 1 & & & & 1 & 1 & \\
\hline Aartrijke & 1 & & & 1 & & & & & & \\
\hline Vladslo & 2 & & & 1 & & & & & & 1 \\
\hline Keiem & 1 & & & & & & & 1 & & \\
\hline Leke & 4 & & & 1 & 1 & & 1 & & & 1 \\
\hline Schore & 4 & & & 2 & & 1 & & & 1 & \\
\hline Zevekote & 2 & & & 2 & & & & & & \\
\hline Moere & 2 & & 2 & & & & & & & \\
\hline Gistel & 2 & & & 1 & & & & & & 1 \\
\hline Slijpe & 7 & & 1 & 1 & 1 & 2 & & 2 & & \\
\hline Snaaskerke & 1 & & & 1 & & & & & & \\
\hline Leffinge & 3 & & & & 1 & & & & 1 & 1 \\
\hline Middelkerke & 2 & & & & & & & & 2 & \\
\hline Wilskerke & 1 & & 1 & & & & & & & \\
\hline Mannekensvere & 2 & & 2 & & & & & & & \\
\hline Oostende & 5 & & 4 & & & & & & & 1 \\
\hline Bredene & 3 & & 1 & & & 1 & & & 1 & \\
\hline Zandvoorde & 3 & & 1 & & & & 1 & 1 & & \\
\hline Oudenburg & 2 & & & & & 2 & & & & \\
\hline Sint-Andries & 1 & & & & & & & & & 1 \\
\hline Varsenare & 1 & & & & & & & & & 1 \\
\hline \multirow[t]{2}{*}{ Waardamme } & 1 & & & & & & & & & 1 \\
\hline & 71 & 1 & 16 & 15 & 3 & 9 & 3 & 7 & 6 & 11 \\
\hline$\%$ & 100 & 1,4 & 22,5 & 21,1 & 4,2 & 12,6 & 4,2 & 9,8 & 8,4 & 15,5 \\
\hline \multicolumn{11}{|l|}{ TOTAAL (der } \\
\hline 3 kwartieren) & 142 & 20 & 27 & 25 & 8 & 17 & 4 & 11 & 11 & 19 \\
\hline$\%$ & 100 & 14,0 & 19,0 & 17,6 & 5,6 & 11,9 & 2,8 & 7,7 & 7,7 & 13,3 \\
\hline
\end{tabular}


Met deze gegevens, die zowel met leen als met eigendom rekening houden, komen wij voor 't Brugse Vrije tot volgende indeling van het bodembezit : 50,6 \% - 72 personen - bezitten minder dan 6 gemeten. Twintig (14 \%) hiervan beschikken over geen gronden. Acht personen $(5,6 \%)$ bezitten 6 tot 9 gemeten, terwijl $30,1 \%-43$ eenheden - van 9 tot 30 gemeten bezitten. Negentien personen of $13,3 \%$ hebben meer dan 30 gemeten ter beschikking. In het Oost-Vrije komt het hoogste percentage bezitlozen voor terwijl ook het percentage van de hoogste categorie van bezitters zeer aanzienlijk is. In het Noord-Vrije zijn geen bezitlozen. Evenmin vinden wij er veel belangrijk grootgrondbezit. Kleine uitbatingen (3,1-6 en 9,1 tot 12 gemeten) vormen er verreweg de belangrijkste groep. De groep der grootgrondbezitters is zeer aanzienlijk in het West-Vrije, terwijl bezitlozen in slechts te verwaarlozen aantal voorkomen (1). Het kleine grondbezit (0,1-6 gemeten is er zeer belangrijk : $43,6 \%$.

Veel van de bezittingen zijn belast, gewoonlijk met verplichtingen in geld, eerder uitzonderlijk met verplichtingen in natura. Globaal is het goed van $59,1 \%$ der plattelandsbewoners belast ; per kwartier zijn de procenten : 52,1 voor het Noordkwartier, 41,6 voor het Oostkwartier en 73,2 voor het Westkwartier. Of die grotere belasting als één der redenen voor de intensievere deelname aan de opstand door het West-Vrije mag worden beschouwd lijkt eerder twijfelachtig. Bij nadere ontleding blijkt inderdaad dat vooral de grotere bezittingen belast zijn. Aan de oorsprong van die belasting ligt dan vaak de stichting van een kapelanie, een fundatie, renten te betalen aan de grafelijke brieven en spijker, een erkenningscijns of tiend $\left({ }^{2}\right)$.

De bezittingen van de stadsbewoners, zoals gezegd meestal huizen, zijn uiteraard minder vaak belast. Toch is het ook hier weer zo dat vooral de eigendommen van de personen die blijkens naam

(1) Vanzelfsprekend is "bezitlozen" hier gebruikt in de betekenis van personen die geen grondbezit hebben. Boven werd er reeds op gewezen dat bezitlozen systematisch uit de lijst zouden kunnen weggelaten zijn.

(2) De cijfers, gelezen uit de bron (zie de op blz. 1131, n. 3 vermelde tekstpublikatie, passim) zijn : 12 op 23 in het Oostkwartier; 20 op 48 in het Noordkwartier; 52 op 71 in het Westlwartier). 
en eigendomsbeschrijving tot de rijksten behoren, belast zijn ( ${ }^{1}$ ). Men krijgt alles bij elkaar de indruk dat alleen de meest kredietwaardigen tot de belasting van hun bezittingen (kunnen) overgaan.

De belaste eigendommen zijn bovendien meestal ten voordele van meer dan één (gemiddeld nagenoeg twee) personen of instellingen belast. Belasting t.v.v. particulieren - vaak niet met name genoemde personen, de graaf en de grafelijke brieven, t.v.v. kapelanieën en abdijen komen vooral in het Oostkwartier voor; in het Noordkwartier komt vooral belasting t.v.v. particulieren voor, wat eveneens het geval is in het West-Vrije, waar nochtans tevens opmerkelijk veel belastingen voorkomen ten voordele van geestelijke en wereldlijke heren en ten voordele van kerken.

Zoals gezegd lijken deze belastingen ons echter geen teken van nijpend gebrek te zijn, maar veeleer van kredietwaardigheid en solvabiliteit.

De bedragen waarmee de goederen belast zijn kunnen ons geen inzicht geven in de waarde van de bezittingen; het tijdstip tot waar de belasting opklimt, de al of niet aanpasbaarheid van de bedragen, en, - in de simplistische veronderstelling dat alle bedragen betrekking hebben op een "contemporain» aangegane belasting - de aard en het karakter van de personen die de verplichting aangingen (al of niet grote vrijgevigheid bij een stichting, al of niet grote neiging om eerder groot krediet op te nemen bij kredietopening) zijn ons immers onbekend.

Belangrijker voor de waarde van de grond zijn misschien de bedragen waartegen een aantal percelen opnieuw verpacht worden voor een termijn van drie jaar. De bedragen van deze pacht (in de Franse tekst « cense », hoewel blijkens de inhoud en bepalingen geen cijns) zijn dan uitgedrukt ofwel voor het totale eigendom ofwel per gemet en per jaar. Het jaarlijks bedrag dient in twee termijnen te worden voldaan : op 24 juni (Sint-Jan) en op 1 oktober (Sint-Baafs) d.w.z. onmiddellijk vóór en onmiddellijk na de oogst $\left({ }^{2}\right)$.

(1) Vermelden wij bij wijze van voorbeeld slechts de bezittingen van Jan van Dudzele, Willem van Oostkamp en Gillis van Rumbeke te Brugge.

(2) De financiële last van het kort op elkaar volgen van de beide hier vermelde betaaltermijnen verliest aan betekenis wanneer wij bedenken dat de cerste vóor, de tweede na de nieuwe oogst valt. 
Noch het dicht op elkaar volgen van de betaaltermijnen, noch de gevraagde prijs leken voor de pachters evenwel veel bezwaren mee te brengen : het gebeurt immers dikwijls dat de echtgenote of een bloedverwant(e) van de persoon wier bezittingen werden in beslag genomen de goederen in pacht neemt ( $\left.{ }^{1}\right)$. Wij moeten aannemen dat de pachtprijs in geval van belasting van de bezitting bij dit laagste bedrag moet worden opgeteld om de totale uitgave, die ten laste van de pachter zal vallen, te verkrijgen ( $\left.{ }^{2}\right)$.

Aldus komen wij tot volgende kostprijs voor het uitbaten in de hierna vermelde localiteiten $\left({ }^{3}\right)$ :

\begin{tabular}{|c|c|c|c|c|c|}
\hline \multirow{3}{*}{$\begin{array}{l}\quad \text { Localiteit } \\
\text { Heile } \\
\text { Sint-Katharina }\end{array}$} & \multicolumn{2}{|r|}{$\begin{array}{l}\text { Uitgebate } \\
\text { oppervlakte }\end{array}$} & \multicolumn{2}{|c|}{ Totale prijs } & \multirow{2}{*}{$\begin{array}{r}\text { Prijs per gemet. } \\
\pm 0.14 .4 \text { lb. par. }\end{array}$} \\
\hline & \multicolumn{2}{|c|}{9 gemeten } & 6.9 .0 & lb. par & \\
\hline & \multicolumn{2}{|c|}{2 gem. 2 linen } & 1.8 .4 & & \pm 0.10 .8 \\
\hline Klemskerke & 3 & $\begin{array}{l}2 \text { linen } \\
1\end{array}$ & 2.8 .3 & & 0.14 .6 \\
\hline Kockelare & 17 & & 14.0 .6 & & 0.16 .6 \\
\hline Koekelare-Ichtegem & 4 & & 1.8 .10 & & \pm 0.7 .2 \\
\hline Leke & & $1 / 2$ & & & 0.19 .4 \\
\hline \multirow[t]{2}{*}{ Schore } & 5 & & 5.5 .0 & & 1. 1.0 \\
\hline & 5 & & 5.3.0 & & \pm 1.0 .8 \\
\hline \multirow[t]{7}{*}{ Slijpe } & 18 & $1 / 2$ & 12.1.2 & & 0.13 .4 \\
\hline & 10 & gem. 1 line 0 & 0 r. 5.6 .6 & & 0.10 .3 \\
\hline & 11 & $1 / 2$ & 13.8 .0 & & 1. 3.4 \\
\hline & 9 & & 9.4 .6 & & 1. 6.0 \\
\hline & 4 & & & & 0.18 .4 \\
\hline & 16 & & & & 0.16 .0 \\
\hline & 2 & & & & 0.13 .4 \\
\hline Snaaskerke & 4 & $1 / 2$ & & & 1. 0.0 \\
\hline Leffinge & 6 & $\mathbf{0}$ & 4.2 .0 & & \pm 0.13 .3 \\
\hline Middelkerke & 26 & & & & 0.14 .0 \\
\hline Mannekensvere & 3 & & & & 0.18 .0 \\
\hline Oostende & 2 & 2 & 2.7 .2 & & \pm 0.18 .0 \\
\hline Varsenare & 35 & & & & 0.13 .0 \\
\hline
\end{tabular}

(1) Dit is o.m. het geval voor het goed van Willem Drinchuut te Klemskerke en voor het bezit van Henri Domas te Vladslo.

(2) Zie bvb. Hughe Harnart te Heile, Maroie f. Willems en Lamsin Wetin te Koekelare.

(3) Wij hebben voor het opstellen van bijgaande lijst alleen « zuivere prijzen " weerhouden, met weglating van o.m. alle bexittingen die renten of betaling in natura verschuldigd waren. 
Deze gegevens zijn voor de bepaling van de grondwaarde slechts van betrekkelijk belang, zeker voor wat de gronden in het OostVrije en het Noord-Vrije betreft, waar wij slechts én gegeven releveerden. De grond lijkt er met uitzondering voor het kleine bedrijf te Sint-Katherina-IJzendijke nagenoeg 3/4 1b. par. per gemet waard.

Belangrijker zijn de gegevens voor het West-Vrije, waar, naargelang zijn kostprijs, de grond in volgende categorieěn kan ingedeeld worden :

$\begin{array}{ll}4-8 \text { solidi par./gemet } & 1 \\ 8-12: & 1 \\ 12-16: & 6 \\ 16-20: & 6 \\ 20-24: & 4\end{array}$

De gemiddelde grondwaarde is hier dus 16 tot $18 \mathrm{~s}$. par. per gemet $\left(^{1}\right)$. Het grondbezit lijkt er dus enigszins belangrijker dan in de andere kwartieren, en, in vergelijking met de prijs in deze kwartieren is die in 't West-Vrije zeer goed aanvaardbaar. De minder vruchtbare gronden - «Une povre maison et 4 mesures de terre », wellicht een deel van de wastine "Utfang " te Koekelare - Ichtegem, en gronden te Varsenare - brengen het minst op, terwijl vruchtbaarder gronden een hogere eenheidsprijs per gemet lijken te bereiken.

Vergelijken wij tenslotte de gegevens, in de confiscatierekening van 1329 voor het Brugse Vrije vervat, met de gegevens voor andere gebieden uit dezelfde periode.

Het dichtst bij, in de kasselrij Veurne, waren volgens G. Des Marez van 1072 bezitters van eigendommen 58,6\% die minder dan 2,2 ha. bezaten; $23,1 \%$ beschikten over 2,2 tot 4,4 ha ; $16,4 \%$ hadden een bezit tussen 4,4 en 13,2 ha. Ten slotte bezaten $2 \%$ meer dan 13,2 ha $\left({ }^{2}\right)$.

(1) Als enige uitzondering hierop zou men de waarde 0.10 .3 lb. par. te Slijpe kunnen aanvoeren.

(2) G. Des Marez, op. cit., blz. 176-181. Voor Nieuwpoort bestaat cen afzonderlijke studie: R. Degryse, De sociale stand van de Nieuwpoortse strijders van 1328, Bachten de Kupe, V, nr. 4-5, 1963, 6 blz. (overdruk). 
In de kasselrij Sint-Winoksbergen waren de verhoudingen, berekend naar de cijfers, vermeld door L. Hendrickx ( $\left.{ }^{(}\right)$:

\begin{tabular}{lrr}
\hline Minder dan 2,2 ha. & 490 & $62,8 \%$ \\
$2,2-4,4$ ha. & 164 & $21,0 \%$ \\
$4,4-13,2$ ha. & 112 & $14,3 \%$ \\
meer dan 13,2 ha. & 14 & $1,8 \%$ \\
\hline
\end{tabular}

In de kasselrij Cassel komen wij, volgens dezelfde gegevens, tot:

\begin{tabular}{lrr}
\hline minder dan 2,2 ha. & 61 & $44,8 \%$ \\
$2,2-4,4$ ha. & 35 & $25,7 \%$ \\
$4,4-13,2$ ha. & 37 & $27,2 \%$ \\
meer dan 13,2 ha. & 3 & $2,2 \%$ \\
\hline
\end{tabular}

Van de 1238 bezitters in de kasselrij Kortrijk, ongeveer een halve eeuw later, zijn er : 684 die minder bezitten dan 2,8 ha. ( 2 bunders). 81 bezitten meer dan 9 bunders (ongeveer 12,75 ha.), terwijl de groep hiertussen gelegen ongeveer 473 eenheden omvat. Van deze laatste groep zijn er 149 die tussen 2,8 en 4,2 ha. bezitten ${ }^{(2)}$.

Dit geeft in tabelvorm :

\begin{tabular}{lrl}
\hline minder dan 2,8 ha. & 684 & $55,2 \%$ \\
$2,8-4,2$ ha. & 149 & $12,0 \%$ \\
$4,2-12,7$ ha. & 324 & $26,1 \%$ \\
meer dan 12,7 ha. & 81 & $6,5 \%$ \\
\hline
\end{tabular}

In het Gentse, bij het begin van dezelfde eeuw, bezat de meerderheid van de bezittende boeren 2 tot 3 ha. $\left({ }^{3}\right)$. Op hetzelfde tijdstip hadden $43 \%$ van de mannen van Sint-Bertijns te Beuvrequin minder dan 2 ha. $\left.{ }^{4}\right)$.

(1) L. Hendrickx, op. cit., blz. 89.

(2) E. SABBE, Grondbezit en landbouzw. Economische en sociale toestanden in de kastelenij Kortrijk op het einde der XIV eeuw, Handelingen Kon. Geschied - en Oudheidk. kring Kortrijk, n.r. XV, 1936, blz. 394-458 en vooral blz. 401.

(3) A. Verfulst, De Boeten, I. De Middeleeuwen, Flandria Nostra, I, AntwerpenBrussel, 1957, blz. 107.

(4) G. W. Cooprand, The abbey of St.-Bertin and its neighbourhood 900-1350, Oxford, 
In het Naamse hebben wij volgende toestand ( $\left.{ }^{1}\right)$ :

Tot 3 bunder

$4-5$ bunder

$6-15$ bunder

meer dan 15 bunder
158

34

63

24
$56,6 \%$

$12,1 \%$

$22,5 \%$

$8,6 \%$

Aan de overzijde van het kanaal is de toestand als volgt: de houders van Glastonbury op Avalon zij ten getale van 610 ; hiervan houden $350(57,5 \%)$ minder dan 2 ha. ( $\left.{ }^{2}\right)$.

In het Brugse Vrije bezitten - van de 113 plattelandsbewoners die over grondeigendommen beschikken $\left({ }^{3}\right)-45,9 \%$ (tweeënvijftig) minder dan 6 gemeten; 10,6\% bezitten 6 tot 9 gemeten, terwijl evenveel personen (twaalf of 10,6\%) meer dan 13,27 ha. (30 gemeten) bezitten. Zevenendertig personen (32,7 \%) hebben een oppervlakte tussen 9 en 30 gemeten.

\section{Besluit :}

Afgezien van de bezitlozen waarvan wij het aandeel op grond der ter beschikking staande bronnen niet durven bepalen, behoren de personen die aan de opstand van Kust-Vlaanderen deelnamen, tot de betere sociale laag der vrije boeren ( $\left.{ }^{4}\right)$.

1914, blz. 77. - Zie ook B. Slicher van BATH, De agrarische geschiedenis van West-Eruropa, Utrecht-Antwerpen, 1960, blz. 150-151.

(1) L. GENicot, Exploitations agricoles dans la comte de Namur, Etudes rurales, V-VI, 1962, blz. 5-31. Het gaat hier over gegevens die de gemeenten Flavion, Haltinne en Viesville betreffen. Bij de invoering van het metriek stelsel was het bunder in de gemeenten van het oude graafschap Namen 0,9462 ha.

(2) M. Postan, Some economic evidence of declining population, The economic History Reviez, 2 nd. series II, 1950, blz. 242.

(3) Tabel III.

(4) Tot deze conclusie kwamen H. Pirenne en L. Hendrickx, terwijl G. Des Marez veeleer het tegenovergestelde verdedigde. (Zie L. Hendrickx, op. cit., blz. 90). Voor de gebeurtenissen van de opstand in het algemeen : zie H. VAN Werveke in Algemerze Geschiedenis der Nederlanden, III, blz. 27-46. Pleimion Naibn, Zannekin en de orijheidsstrijd van het kustland van 1323 tot 1328, z.d. (1928), is vulgariserend, terwijl F. HuaenhoLTz, Drie Boerenopstanden uit de veertiende eeuw, Leiden, 1949, het karakter van de opstandige beweging onderzoekt. 
Tenzij de graaf een mildere confiscatiepolitiek zou gevoerd hebben dan de Franse koning - wat a priori niet mag verworpen worden - was de opstandige beweging geconcentreerd in de ambachten Veurne, Cassel en Bergues. In het Brugse Vrije nam slechts een minderheid aan de opstand deel en dit in afnemende mate, naarmate het gebied verder periferisch t.o.v. het opstandig gebied lag. Bovendien is het zeer waarschijnlijk dat nog andere confiscatielijsten hebben bestaan (1).

TABEL III

Aantal en Percentage Grondbeztrters per Bezrtskiasse

\begin{tabular}{lrrr}
\hline $\begin{array}{c}\text { Bezit } \\
\text { (in gemeten) }\end{array}$ & Aantal & & $\%$ \\
& & $(1)$ & $(2)$ \\
\hline 0 & 29 & 20,4 & - \\
$0,1-3$ & 24 & 16,9 & 21,2 \\
$3,1-6$ & 28 & 19,7 & 24,7 \\
$6,1-9$ & 12 & 8,4 & 10,6 \\
$9,1-12$ & 13 & 9,1 & 11,5 \\
$12,1-15$ & 4 & 2,8 & 3,5 \\
$15,1-21$ & 11 & 7,7 & 9,7 \\
$21,1-30$ & 9 & 6,9 & 8,0 \\
30 en meer & 12 & 8,4 & 10,6 \\
\hline
\end{tabular}

(1) Percentage berekend op het totaal aantal in de bron vermelde personen $(142=$ $100 \%)$.

(2) Percentage berekend op het aantal bezitters van eigendommen - dus met weglating van hen die geen eigendommen bezaten $(113=100 \%)$.

Buiten het belang van de lijst der inbeslagnemingen voor de kennis van de opstand van Kust-Vlaanderen zelf, heeft zij - op zichzelf beschouwd - belang voor de economische en sociale stratificatie in de late middeleeuwen. Indien deze lijst een doorsnede moest geven van een populatie (in de statistische betekenis van de term), representatief voor het geheel van de bevolking, dan zou hieruit afgeleid mogen worden dat de bezitsverhoudingen op het platteland in de omgeving van Brugge ongeveer zijn als weerge-

(1) Zie o.m. H. Prrenne, op. cit., blz. lxix ; D. De Pauw, op. cit., en H. Stenn, op. cit. Zie ook blz. 1140, n. 2. 
geven in tabel op blz. 1144 ; dat de stedelingen vaak eigenaar waren van een huis of van een deel ervan, maar zelden van enig ander onroerend goed; dat slechts een fractie van de bevolking een leen van kleine afmetingen bezat en dat ongeveer $4,2 \%$ van de bevolking aanzienlijke lenen bezat.

TABel IV

Aantal en percentage leenhouders per kLAsse van uttoestrektheid Van leen

\begin{tabular}{lrrr}
\hline $\begin{array}{c}\text { Bezit } \\
\text { (in gemeten) }\end{array}$ & Aantal & $(1)$ & $\%$ \\
\hline 0 & & 78,9 & $(2)$ \\
\hline $0,1-3$ & 112 & 7,7 & - \\
$3,1-6$ & 11 & 4,2 & 36,6 \\
$6,1-9$ & 6 & 2,1 & 20,0 \\
$9,1-12$ & 3 & 0,7 & 10,0 \\
$12,1-15$ & 1 & 0,7 & 3,3 \\
$15,1-21$ & 1 & 0,7 & 3,3 \\
$21,1-30$ & 1 & 0,7 & 3,3 \\
30 en meer & 1 & 4,2 & 3,3 \\
\hline
\end{tabular}

(1) Percentage berekend op het totaal aantal in de bron vermelde personen $(142=$ $100 \%)$.

(2) Percentage berekend op het aantal leenhouders - dus met weglating van hen die geen lenen hielden $(30=100 \%)$.

Bij vergelijking met een viertal groepen, waarvan het bezit met de bezitsgroepen in het Brugse Vrije kan vergeleken worden, blijkt dat de algemene bezitsstructuur niet opzienbarend afwijkt van de toestand elders. Gewoonlijk treffen wij een grote groep (vaak meer dan $50 \%$ ) personen aan met zeer weinig uitgebreid grondbezit, gevolgd door een kleine groep, die de tweede bezitsklasse uitmaakt, door een derde, meer uitgebreide groep met belangrijker bezit en door een kleine laatste groep van belangrijkste grondbezitters. Ook in het Brugse Vrije heerst, bij grove indeling, dezelfde groepsverhouding. Evenwel is de groep der laagste bezitsklasse minder talrijk dan elders, terwijl de klasse der belangrijkste grondbezitters talrijker is. Van beide middengroepen overtreft die van personen met het grootste bezit de andere in veel aanzienlijker mate dan elders. 
Samenvattend kan men besluiten dat ook hier nog eens blijkt dat Pirenne zich bij de sociale waardering van de deelnemers aan de opstand waarschijnlijk niet heeft vergist. Evenwel was de toestand in het Brugse Vrije nog minder precair dan elders in de aan de opstand deelnemende gewesten. In hoeverre dit als medeoorzaak voor een gebeurlijk minder talrijke deelname van het Brugse Vrije kan ingeroepen worden, moeten wij hier echter in het midden laten (1).

\section{J. Mertens.}

(1) Gaarne spreek ik mijn dank uit tegenover Prof. Verhulst, die de tekst van deze studie heeft willen nalezen. Tevens dank ik mijn collega Drs. Danhieux en Drs. J. Sabbe, met wie ik tot mijn profijt in de loop van het onderzoek sommige problemen heb kunnen bespreken. 